\title{
SUPERAÇÃO DE DORMÊNCIA EM SEMENTES DE Zeyheria montana Mart.
}

\author{
Dormancy break in Zeyheria montana Mart. seeds
}

\author{
Sara Dousseau ${ }^{1}$, Amauri Alves de Alvarenga ${ }^{2}$, Evaristo Mauro de Castro ${ }^{3}$, \\ Lúcio de Oliveira Arantes ${ }^{1}$, Fernanda Carlota Nery ${ }^{4}$
}

\begin{abstract}
RESUMO
Zeyheria montana Mart. (Bignoniaceae) é uma espécie medicinal conhecida como bolsa de pastor que se encontra com risco de extinção, sendo fundamental o desenvolvimento de metodologias para sua propagação e preservação. Neste estudo, avaliou-se a porcentagem de germinação e o índice de velocidade de germinação de sementes de bolsa de pastor submetidas à diferentes métodos de superação de dormência: lavagem por diferentes períodos, retirada total e parcial da expansão alada, combinação de lavagem com retirada parcial da expansão alada e imersão em ácido clorídrico e sulfúrico, em diferentes concentrações. Como testemunha, utilizaramse sementes intactas. $\mathrm{O}$ experimento foi conduzido em câmara de germinação do tipo $\mathrm{BOD}$, temperatura de $25^{\circ} \mathrm{C}$, fotoperíodo de 12 horas e $100 \%$ de UR. Sementes submetidas à lavagem em água corrente por 6 horas, com a retirada parcial da expansão alada, tiveram vigor e porcentagens de germinação superiores aos outros tratamentos. Os resultados demonstram que a causa de dormência em sementes dessa espécie é complexa, sendo causada por interferência no alongamento embrionário e possível presença de inibidores.
\end{abstract}

Termos para indexação: Planta medicinal, dormência mecânica, inibidor.

\section{ABSTRACT}

Zeyheria montana Mart. (Bignoniaceae) is a medicinal species known as "bolsa de pastor" which found itself in of extinction, being essential the development of methodologies for its propagation and preservation. In this study, one evaluated the percentage of germination and speed germination index from "bolsa de pastor" seeds submitted to different methods of scarification: washing for different periods, partial and total removal of ala expansion, combination of washing with partial and total removal of ala expansion and, immersion in cloridric and sulfuric acid in different concentrations. The intact seeds were used as control. The experiment was conducted in germination chamber, BOD model, regulated at $25^{\circ} \mathrm{C}, 12$ hours photoperiod and RH at $100 \%$. Seeds submitted to washing in taping water for 6 hours with the partial removal of ala expansion showed higher vigor and germination percentage in relation to other treatments. The results suggest that the cause of dormancy in seeds of this species is complex, being caused by the embrionary stretching and possible presence of inhibitors.

Index terms: Medicinal plant, mechanical dormancy, inhibitor.

(Recebido em 18 de maio de 2006 e aprovado em 26 de janeiro de 2007)

\section{INTRODUÇÃO}

Zeyheria montana Mart. (Bignoniaceae) é uma espécie medicinal endêmica do cerrado brasileiro. O extrato aquoso de suas raízes é indicado, pela medicina popular, no combate de doenças de pele e como agente anti-tumoral (Corrêa, 1984). Suas raízes e caule possuem diversos tipos de naftoquinonas, majoritariamente o lapaxol, que possui atividade comprovada como antiinflamatória, anti-úlcera gástrica, anti-neoplásica e antimicrobiana (Almeida et al., 1990; Favaro et al., 1990; Goel et al., 1987; Oliveira et al., 2001).

A emergência das plântulas dessa espécie é consideravelmente lenta e variável de acordo com a distribuição da espécie, sendo que a retirada da expansão alada é fundamental para a germinação (BERTONI, 2003). Entretanto, na literatura, constata-se uma carência generalizada de informações no que diz respeito à fisiologia da germinação de suas sementes.

Ao considerar o processo germinativo de uma semente, alguns fatores extrínsecos (ambientais) e intrínsecos (sementes) devem ser considerados. A dormência geralmente está associada a fatores intrínsecos, ligados à própria semente, como dureza e impermeabilidade do tegumento à água e gases, embrião imaturo, presença de inibidores e aos fatores extrínsecos, tais como temperatura, luz, umidade e substrato (BEWLEY \& BLACK, 1994).

\footnotetext{
${ }^{1}$ Mestrandos do Departamento de Biologia/DBI - Universidade Federal de Lavras/UFLA - Cx. P. 3037 - $37.200-000$ - Lavras, MG saradousseau@yahoo.com.br; lucio arantes@yahoo.com.br

2Doutor, Professor Associado do Departamento de Biologia/DBI - Universidade Federal de Lavras/UFLA - Cx. P. 3037 - $37.200-000$ - Lavras, MG amauriaa@uflanet.br

${ }^{3}$ Doutor, Professor do Departamento de Biologia/DBI - Universidade Federal de Lavras/UFLA - Cx. P. 3037-37.200-000 - Lavras, MG - emcastro@ufla.br ${ }^{4}$ Doutoranda do Departamento de Biologia/DBI - Universidade Federal de Lavras/UFLA - Cx. P. 3037 - $37.200-000$ - Lavras, MG fernandacarlota@yahoo.com.br
} 
A dormência assume papel relevante, de um lado por sua função ecológica, pois constitui um mecanismo de sobrevivência das espécies, assegurando sua viabilidade até que as condições ambientais sejam adequadas para o estabelecimento e crescimento da plântula. Por outro, constitui-se em um impedimento à pronta germinação, prejudicando a produção de mudas em larga escala (POPININGIS, 1985).

Para escolha do método utilizado na superação da dormência é indispensável identificar os fatores responsáveis pelo impedimento à germinação. Em sementes com tegumento impermeável à água e a gases e/ou conferindo resistência à expansão do embrião, os métodos empregados devem promover aberturas ou eliminação completa desse, como ocorre com a escarificação química ou mecânica.

Quando à dormência é ocasionada por um balanço desfavorável entre promotores e inibidores de germinação, métodos que aumentem a concentração dos promotores ou que atuem impedindo a ação dos inibidores deverão ser empregados, como é o caso da estratificação, lixiviação e aplicação direta de citocinina e/ou giberelina (FERREIRA \& BORGHETTI, 2004).

Inúmeros trabalhos são encontrados na literatura (BARBOSA et al., 2005; COSTA et al., 2005; SMIDERLE et al., 2005), estudando a germinação das sementes de respectivamente, Acacia mangium Willd. (acácia), Strelitzia reginae Ait (ave-do-paraíso) e Ceratophyllum demersum L. (rabo de raposa), cujos resultados indicaram a presença de dormência nas sementes e a necessidade de diferentes métodos para superá-la.

Objetivou-se neste estudo determinar a natureza da dormência e o efeito de diferentes métodos de superação dela sobre a porcentagem de germinação e o índice de velocidade de germinação nas sementes de Zeyheria montana Mart.

\section{MATERIAL E MÉTODOS}

Os experimentos foram conduzidos no Laboratório de Crescimento e Desenvolvimento de Plantas do Departamento de Biologia da UFLA. Os frutos foram coletados de 30 plantas localizadas no município de IjaciMG, em uma reserva particular de cerrado, durante o período de dispersão (setembro/novembro) de 2005, e permaneceram por 12 horas, em condições de laboratório, para completa deiscência.

Para eliminar dormência mecânica, utilizou-se a escarificação química e manual. No primeiro caso, as sementes foram imersas em diferentes concentrações de ácido sulfúrico-98\% pa e clorídrico-71\% pa (20, 25, 50 e
$100 \%$ ), por 5 minutos, e posteriormente lavadas em água corrente por 10 minutos. Para a escarificação manual, retirou-se totalmente e parcialmente a expansão alada. Como testemunha, utilizaram-se sementes intactas.

Para retirar-se possíveis inibidores, as sementes foram submetidas à lavagem em água corrente por 6 e 12 horas. Contudo, para lixiviar inibidores e eliminar a resistência mecânica do tegumento, além da lavagem em água corrente por esses dois períodos, procedeu-se à retirada parcial da expansão alada.

O teste de germinação foi realizado em sistema de rolo, sendo as sementes distribuídas sobre folhas de papeltoalha $\left(\right.$ Germitest $\left.^{\circledR}\right)$, previamente umedecido em água destilada na razão de 2,5 vezes a massa do papel seco. Os rolos foram mantidos na posição vertical em béquer de 1 litro, com uma lâmina de água destilada de $1 \mathrm{~cm}$ no fundo e cobertos com um saco plástico transparente para garantir $100 \%$ de umidade.

O experimento foi conduzido em câmara de germinação tipo BOD, sob temperatura de $25^{\circ} \mathrm{C}$, fotoperíodo de 12 horas e $100 \%$ de UR. Utilizou-se o delineamento inteiramente casualizado, com 15 tratamentos e 4 repetições de 25 sementes/rolo.

As avaliações foram realizadas diariamente, por um período de 30dias. Determinaram-se a porcentagem de germinação $(\% \mathrm{G})$, pela protrusão de $0,3 \mathrm{~cm}$ da radícula e o índice de velocidade de germinação (IVG), calculado segundo Maguire (1962).

A análise estatística foi realizada mediante o uso do programa estatístico SISVAR (FERREIRA, 1999). Os dados de germinação foram transformados em arco seno $(\mathrm{x} / 100)^{0,5}$ e o índice de velocidade de germinação em (x + $0,5)^{0,5}$ (BARTLETT, 1936; ZAR, 1999). Foi realizada a análise de variância e as médias foram comparadas pelo teste de Scott-Knott, a 5\% de probabilidade (SCOTT \& KNOTT, 1974).

\section{RESULTADOS E DISCUSSÃO}

Apresentam-se na Figura 1, porcentagens de germinação das sementes submetidas à diferentes métodos de escarificação. Sementes imersas em ácido sulfúrico e ácido clorídrico a $100 \%$ não germinaram por causa do efeito deletério às sementes, causando morte das mesmas.

A menor porcentagem de germinação ocorreu em sementes imersas em ácido clorídrico 50\% (9\% G), seguida de ácido sulfúrico $50 \%(26 \%$ G) e em sementes intactas $(30 \% \mathrm{G})$, sendo que os dois últimos tratamentos não diferiram entre si. A imersão em ácidos sulfúrico e clorídrico a 20 e $25 \%$ e lavagem por 6 e 12 horas sem posterior 
escarificação, conferiram baixas porcentagens de germinação e não diferiram entre si, sendo todos inferiores a $47 \% \mathrm{G}$.

As maiores porcentagens de germinação ocorreram em sementes submetidas à lavagem por 6 e 12 horas com posterior escarificação manual parcial e, aquelas submetidas à escarificação manual completa e parcial, que não diferiram entre si, sendo respectivamente, 100, 99, 98\% e $92 \%$ G.

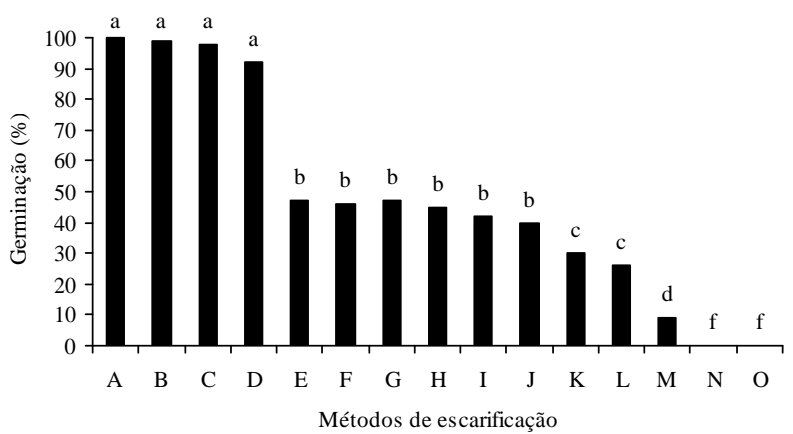

Figura 1 - Porcentagem total de germinação de sementes submetidas a diferentes métodos de superação de dormência. A- lavagem/6h + escarificação manual parcial; B- lavagem $/ 12 \mathrm{~h}$ + escarificação manual parcial; Cescarificação manual completa; D- escarificação manual parcial; E- lavagem/12h; F- lavagem/6h; G- ác. clor. 25\%; H- ác. clor. 20\%; I- ác. sulf. 25\%; J- ác. sulf. 20\%; K- intacta; L- ác. sulf. 50\%; M- ác. clor. 50\%; N- ác. sulf. 100\%; O- ác. clor. $100 \%$. Médias seguidas da mesma letra não diferem entre si pelo teste de Scott-Knott $(\mathrm{p}<0,05)$.

Quanto ao IVG (Figura 2), os ácidos clorídrico e sulfúrico, ambos a 50\%, promoveram os menores valores, não diferindo entre si, sendo respectivamente, 0,15 e 0,31. Sementes imersas em ácido sulfúrico, ácido clorídrico 20 e $25 \%$, lavagem por 6 e 12 horas sem posterior escarificação e intactas conferiram baixos valores e não diferiram entre si, sendo todos inferiores a 0,74. A escarificação manual parcial conferiu o terceiro maior valor de IVG $(2,19)$.

Sementes submetidas à lavagem por 12 horas com posterior escarificação manual e parcial e, aquelas submetidas à escarificação manual completa, apresentaram altos valores de IVG e não diferiram entre si, sendo respectivamente, 3,72 e 3,70. Entretanto a maior velocidade de germinação $(4,70)$ ocorreu em sementes lavadas por 6 horas com posterior escarificação manual parcial, o que permite concluir que esse é o melhor método de escarificação para a superação de dormência dessa espécie.

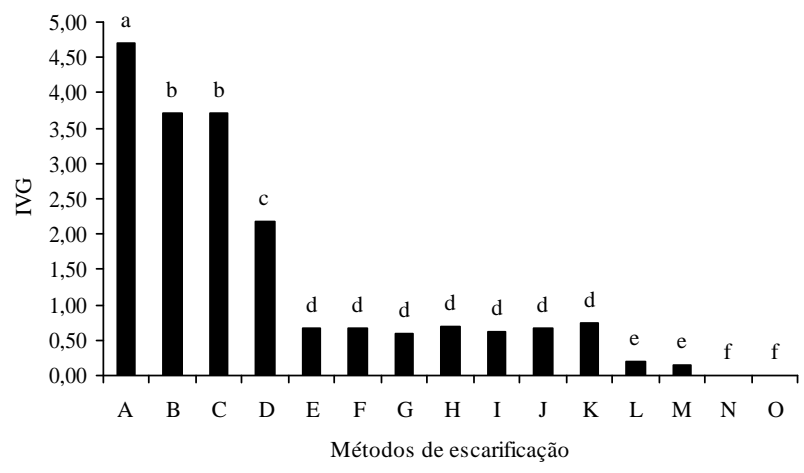

Figura 2 - Índice de velocidade de germinação de sementes submetidas a diferentes métodos de superação de dormência. A- lavagem/6h + escarificação manual parcial; B- lavagem $/ 12 \mathrm{~h}$ + escarificação manual parcial; Cescarificação manual completa; D- escarificação manual parcial; E- lavagem/12h; F- lavagem/6h; G- ác. clor. 25\%; H- ác. clor. 20\%; I- ác. sulf. 25\%; J- ác. sulf. 20\%; K- intacta; L- ác. sulf. 50\%; M- ác. clor. 50\%; N- ác. sulf. 100\%; O- ác. clor. $100 \%$. Médias seguidas da mesma letra não diferem entre si pelo teste de Scott-Knott $(\mathrm{p}<0,05)$.

Como observa-se na Figura 3, o critério utilizado na avaliação da germinação (protrusão de $0,3 \mathrm{~cm}$ de radícula), não reflete realmente o processo quando comparada com as sementes cujos tegumentos foram removidos total ou parcialmente. Isso ocorre pois em sementes intactas, antes mesmo de ser possível a visualização de $0,3 \mathrm{~cm}$ de radícula, no interior do tegumento, ela já atingiu esse comprimento.

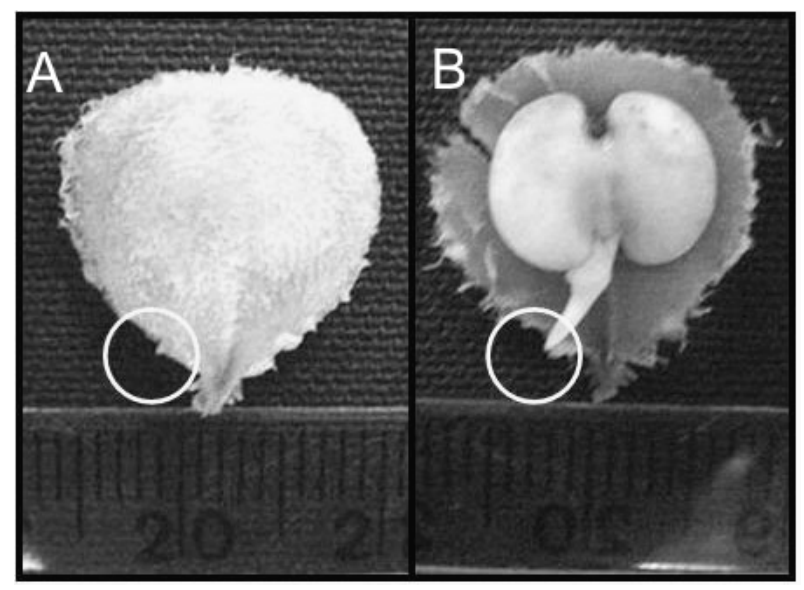

Figura 3 - A - sementes intacta com protrusão apenas da ponta da radícula e, B - protrusão de mais de 0,3 cm após a retirada do envoltório externo.

Tanto o ácido sulfúrico quanto o ácido clorídrico conferem efeito corrosivo ao tegumento da semente o que, 
para muitas espécies é favorável, pois ao alterar-se a permeabilidade da membrana isso permite que a água, fator essencial à germinação seja absorvida, dando início ao processo germinativo, além de tornar possíveis as trocas gasosas e eliminar a resistência mecânica à protrusão da radícula, bem como facilitar a expansão do embrião.

O tempo de exposição ao ácido é variável em função do genótipo e/ou condições de cultivo, pois esses fatores afetam a composição e espessura do envoltório externo (GODOY \& SOUZA, 2004; SILVA et al., 2005). Barbosa et al. (2005) trabalhando com Strelitzia reginae Ait, verificaram que os melhores resultados de germinação e vigor ocorreram em sementes escarificadas em ácido sulfúrico concentrado por 9 minutos, enquanto Boyle \& Hladun (2005), em estudos com Baptisia australis (L.) R. Br., observaram que o tempo de exposição deve ser de 20 a 80 minutos.

Entretanto, para a espécie em estudo, o uso de ácidos, mesmo em baixas concentrações, não foi eficiente para superação da dormência, provavelmente em razão do tegumento apresentar certa porosidade, o que permitiu a absorção rápida dos ácidos, causando efeito deletério ao embrião. Resultados semelhantes foram encontrados por Aduradola et al. (2005) trabalhando com Chrysophyllum albidum (G. Don), que verificaram que quanto maior a concentração e o tempo de tratamento, menor é a porcentagem de germinação.

A lavagem em água corrente é o método de lixiviação, em que se utiliza a água como agente de lixiviação de inibidores hidrofílicos e/ou microrganismos nocivos presentes na semente. É utilizado também, quando se deseja amolecer o tegumento, com o conseqüente aumento da permeabilidade dos envoltórios e do potencial germinativo, o que resulta em maior velocidade de embebição e de germinação. Em condições naturais, tal efeito pode ser obtido quando ocorre uma chuva torrencial ou mesmo chuvas freqüentes, como ocorrem no cerrado, habitat natural da bolsa de pastor (FERREIRA \& BORGHETTI, 2004).

O tempo em que as sementes ficam submetidas à lixiviação deve ser determinado corretamente, pois varia em função das características do tegumento. Para a bolsa de pastor, a lavagem por 12 horas e posterior escarificação manual parcial provocou uma redução no IVG, provavelmente por causa da lavagem de fito-hormônios presentes nas sementes.

Silva et al. (2005), trabalhando com Beta vulgaris L., verificaram que a maior porcentagem de germinação foi obtida quando as sementes foram submersas por duas horas em água corrente, sem, contudo, diferir do percentual obtido com três horas. Entretanto, com 4, 5 e 6 horas, ocorreram decréscimos significativos na porcentagem de germinação, confirmando a necessidade da determinação do período correto de imersão.

A espécie apresenta dormência imposta pelo envoltório externo (expansão alada), que embora não seja duro, é bastante fibroso, causando interferência no alongamento embrionário. Como constata-se na figura 3, a protrusão radicular ocorre, só que a radícula tem que percorrer toda extensão da expansão alada. Durante esse tempo, até a saída da radícula, a semente fica susceptível ao ataque de microrganismos endógenos e/ou exógenos.

Nas sementes intactas, submetidas ou não à lavagem, cria-se um ambiente bastante propício à proliferação de microrganismos entre a expansão alada e o embrião, acarretando apodrecimento das sementes durante o teste de germinação. Esses resultados foram relatados por Bertoni (2003), que encontraram elevados níveis de contaminação por fungos e bactérias endógenas, nas sementes intactas.

Esse fato não é observado em sementes submetidas à lavagem com posterior escarificação parcial. Entretanto, em sementes apenas escarificadas parcialmente observase elevada contaminação microbiana, comprovando que a lixiviação foi eficiente para eliminar os microrganismos endógenos, contudo a retirada parcial torna o ambiente da semente menos favorável à proliferação destes microrganismos.

Nas sementes nas quais se retirou completamente a expansão alada, embora não tenha sido observada contaminação microbiana, há um atraso na germinação. A lavagem das sementes pode ter favorecido o comportamento germinativo atuando na eliminação de inibidores, ou ainda, aumento na flacidez dos envoltórios, facilitando a protrusão da radícula.

Possivelmente, as sementes da espécie em questão, apresentam dormência complexa causada pela presença de inibidores nas sementes e pela resistência mecânica à protrusão da radícula provocada pelo tegumento. Para comprovar a presença de compostos inibidores, deverão ser realizados testes utilizando-se sementes de alface como marcadores biológicos.

A baixa germinação encontrada em sementes intactas quando comparada com as escarificadas, comprova a necessidade do uso de métodos para a superação da dormência. Segundo Ferreira \& Borghetti (2004), testes de germinação realizado com espécies que possuem sementes dormentes podem produzir resultados insuficientes para a correta previsão do comportamento das mesmas frente aos tratamentos impostos. 


\section{CONCLUSÃO}

Pelos resultados obtidos, é possível inferir que a causa da dormência em sementes de bolsa de pastor (Zeyheria Montana Mart.) é de natureza tegumentar, com a possível presença de inibidores. Sendo assim, recomendase a lavagem das mesmas por 6 horas com posterior escarificação manual parcial para a superação da dormência em sementes desta espécie.

\section{REFERÊNCIAS BIBLIOGRÁFICAS}

ADURADOLA, A. M.; ADEOLA, B. F.; ADEDIRE, M. O. Enhancing germination in seeds of African star apple, Chrysophyllum albidum (G. Don). Journal of Food-Agriculture and Environment, [S.1.], v. 3, n. 2, p. 292-294, 2005.

ALMEIDA, E. R.; SILVA FILHO, A. A.; SANTOS, E. R.; LOPES, C. A. Antiinlfamatory action of lapachol. Journal Ethnopharmacol, [S.1.], v. 29, n. 2, p. 239-241, 1990.

BARBOSA, J. G.; ALVARENGA, E. M.; DIAS, D. C. F. S.; VIEIRA, A. N. Efeito da escarificação ácida e de diferentes temperaturas na qualidade fisiológica de sementes de Strelitzia reginae. Revista Brasileira de Sementes, Pelotas, v. 27, n. 1, jun. 2005.

BARTLETT, M. S. The square root transformation in analysis of variance. Journal Royal Statistical Society Supplement, [S.1.], v. 3, p. 68-78, 1936.

BERTONI, B. W. Propagação, variabilidade genética e química de Zeyheria montana Mart. 2003. 165 f. Tese (Doutorado em Genética e Melhoramento de Plantas) Universidade Estadual Paulista, Jaboticabal, 2003.

BEWLEY, J. D.; BLACK, M. Seeds: physiology of development and Germination. 2. ed. New York: Plenum, 1994. $445 \mathrm{p}$.

BOYLE, T. H.; HLADUN, K. Influence of seed size, testa color, scarification method, and immersion in cool or hot water on germination of Baptism australis (L.) R. Br. Seeds. Hortscience, Alexandria, v. 40, n. 6, p. 1846-1849, 2005.

CORRÊA, M. P. Dicionário de plantas úteis do Brasil e das exóticas cultivadas. Rio de Janeiro: Ministério da Agricultura-IBDF, 1984. v. 3, 646 p.

COSTA, N. V.; MARTINS, D.; MARTINS, C. C.; MARCHI, S. R.; DOMINGOS, V. D. Superação de dormência de sementes de Ceratophyllum demersum. Planta Daninha, Viçosa, v. 23, n. 2, abr./jun. 2005.
FAVARO, O. C. N.; OLIVEIRA, M. M.; ROSSINI, M. A. A.; KAMAKURA, C. R.; PINTO, A. V.; PINTO, M. C. F. R. Seleção por meio de células KB de substancias e extrato potencialmente ativo em quimioterapia do câncer. Academia Brasileira de Ciência, Rio de Janeiro, v. 62, n. 3, p. 217-224, 1990.

FERREIRA, A. G.; BORGHETTI, F. Germinação: do básico ao aplicado. São Paulo: Artmed, 2004. 323 p.

FERREIRA, D. F. SISVAR - Sistema de analises estatísticas. Versão 4.3. Lavras: UFLA, 1999.

GODOY, R.; SOUZA, F. H. D. Dormência em sementes de guandu (Cajanus cajan (L.) Millsp). Revista Brasileira de Zootecnia, Viçosa, v. 33, n. 6, nov./dec. 2004. Suplemento 3.

GOEL, R. K.; PATHAAK, N. K.; BISWAS, M.; PANDEY, V. B.; SANYAL, A. K. Effect on lapachol, a naphtaquinone isolated from Tectona grands on experimental pectic ulcer and gastric secretion. Journal of Pharmacy and Pharmacology, [S.1.], v. 39, n. 2, p. 138-140, 1987.

MAGUIRE, J. D. Speed of germination-aid in selection and evaluation for seedling emergence and vigour. Crop Science, Madson, v. 2, n. 1, p. 176-177, Jan./Feb. 1962.

OLIVEIRA, C. G. T.; MIRANDA, F. F.; FERREIRA, V. F.; FREITAS, C. C.; RABELLO, R. F.; CARBALLIDO, J. M.; CORREAA, L. C. D. Synthesis and antimicrobiol evaluation of 3-hydrazino-naphthoquinones as analogs of lapachol. Journal of the Brazilian Chemical Society, [S.l.], v. 2, n. 3, p. 339-345, 2001.

POPININGIS, F. Fisiologia de sementes. Brasília, DF: Agriplan, 1985. $285 \mathrm{p}$

SCOTT, A. J.; KNOTT, M. A cluster analysis method for grouping means in the analysis of variance. Biometrics, Washington, v. 30, p. 507-512, 1974.

SILVA, J. B.; VIEIRA, R. D.; CECÍLIO FILHO, A. B. Superação de dormência em sementes de beterraba por meio de imersão em água corrente. Horticultura Brasileira, Brasília, v. 23, n. 4, out./dez. 2005.

SMIDERLE, O. J.; MEDEIROS JUNIOR, M.; SOUSA, R. C. P. Tratamentos pré-germinativos em sementes de acácia. Revista Brasileira de Sementes, Pelotas, v. 27, n. 1, jun. 2005.

ZAR, J. H. Biostatistical analysis. 4. ed. New York: Prentice Hall, 1999. 929 p. 